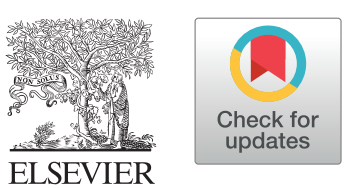

\title{
CJC Open 2 (2020) 432-434 \\ Case Report \\ Embolization to Two Different Vascular Territories in a Patient With Bicuspid Aortic Stenosis Undergoing Transcatheter Aortic Valve Implantation
}

\author{
Murat Cimci, MD, Marco Roffi, MD, and Stephane Noble, MD \\ Structural Heart Unit, Cardiology Division, Department of Medicine, University Hospitals of Geneva, Geneva, Switzerland
}

\begin{abstract}
We describe the case of an 81-year-old man with symptomatic severe bicuspid aortic valve stenosis. Transfemoral transcatheter aortic valve implantation was performed with a cerebral embolic protection device. During valve deployment, the 29-mm Evolut PRO prosthesis (Medtronic) popped out 3 times and exchanged for a 34-mm Evolut R. Large valvular debris were captured in the embolic protection device. Subsequently, the patient developed chest pain and electrocardiogram modification. An emergency coronary angiography showed an occlusion of the middle circumflex artery. This case demonstrates technical challenges and possible complications in patients with bicuspid aortic valve stenosis undergoing transcatheter aortic valve implantation.
\end{abstract}

\section{Case Report}

An 81-year-old man, on steroids for fibromyalgia and known for bladder dysfunction after vertebral trauma, reported shortness of breath on exertion in the context of severe aortic valve stenosis (type 0 bicuspid valve, mean gradient: $37 \mathrm{~mm}$ $\mathrm{Hg}$, valve area: $0.8 \mathrm{~cm}^{2}$, preserved left ventricular ejection fraction). Coronary arteries were normal. The aortic valve calcium score was $2878 \mathrm{UH}$. After Heart Team discussion, we opted for transfemoral transcatheter aortic valve implantation (TAVI) considering the patient's will, age, long-term corticoid therapy, and bladder dysfunction despite low surgical-risk scores (Society of Thoracic Surgeons Predicted Risk of Mortality: $1.4 \%$ and EuroSCORE II: $1.2 \%)$.

Transfemoral TAVI was performed using a 29-mm Evolut PRO valve (Medtronic Inc., Minneapolis, MN) based on the

Received for publication April 17, 2020. Accepted May 16, 2020.

Ethics Statement: The research reported has adhered to the Helsinki ethical principles for medical research involving human beings.

Corresponding author: Dr Stephane Noble, Structural Heart Unit, Cardiology Division, Department of Medicine, University Hospitals of Geneva, Rue Gabrielle-Perret-Gentil 4, 1211 Geneva, Switzerland. Tel.: +41 79 5533149; fax: +4122372 7229 .

E-mail: stephane.noble@hcuge.ch

See page 434 for disclosure information.

\begin{abstract}
RÉSUMÉ
Nous décrivons le cas d'un homme de 81 ans présentant une sténose grave et symptomatique de la valve aortique bicuspide. L'implantation valvulaire aortique par cathéter par la voie transfémorale a été réalisée avec un dispositif de protection embolique cérébrale. Pendant le déploiement de la valve, la prothèse Evolut PRO de $29 \mathrm{~mm}$ (Medtronic) a été sortie en 3 fois et remplacée par une Evolut R de $34 \mathrm{~mm}$. Les gros débris valvulaires ont été capturés dans le dispositif de protection embolique. Par la suite, le patient a développé des douleurs thoraciques et un changement de son électrocardiogramme. Une coronarographie d'urgence a montré une occlusion de l'artère circonflexe. Ce cas illustre les défis techniques et les complications possibles chez les patients présentant une sténose de la valve aortique bicuspide et subissant une implantation valvulaire aortique par cathéter.
\end{abstract}

computed tomography measurements (Fig. 1A). A Sentinel dual filter embolic protection device (EPD) (Boston Scientific, Maple Grove, $\mathrm{MN}$ ) was positioned via the right radial artery in the brachiocephalic trunk and left common carotid artery (activated clotting time $>250 \mathrm{~s}$ ). Balloon aortic valvuloplasty was performed using a $22 \times 40 \mathrm{~mm}$ Nucleus balloon (NuMED, Inc, NY). Three attempts to deploy the valve resulted in pop-outs into the aortic root despite pacing at 150 bpm. We upsized the valve and successfully implanted a 34-mm Evolut R (Fig. 1B). The debris captured by the EPD were $1.5 \mathrm{~cm}$ long, and histopathology analysis revealed that they were valve fragments (Fig. 2A). Once no longer under the effect of sedation in a monitored unit, the patient complained of increasing chest pain. The 12-lead electrocardiogram showed ST-segment elevation in the inferior leads and V6 associated with ST-segment depression in V1-V3 (Fig. 2B). Transfemoral emergency coronary angiography showed acute occlusion of the mid left circumflex (LCX) artery (Fig. 2C). The left main ostium was successfully engaged through the struts of the prosthesis with an Amplatz Left-2 (AL-2) 5-F diagnostic catheter after failure of a Judkins left 4.0, extra backup 3 and 3.5 guiding catheter, and AL-1 diagnostic catheter. To exchange the diagnostic catheter for an AL-2 guiding catheter, an extra-support Sion Blue guidewire (Asahi, Tokyo, Japan) was introduced in the left anterior 


\section{Novel Teaching Points}

- TAVI in BAV is associated with technical challenges regarding transcatheter heart valve sizing and positioning.

- Additional manoeuvres can predispose to debris embolization to different vascular territories.

- Coronary angioplasty may be challenging due to difficult engagement of the coronary ostium, especially after supra-annular valve implantation.

- EPDs can play a particularly important role in preventing cerebrovascular events even more so in BAV, which is often associated with a higher rate of stroke.

descending artery through the diagnostic catheter. Subsequently, using an extension wire (Asahi) on the extra-support Sion Blue and a $0.35^{\prime \prime}$ HI-Torque Supracore guidewire (Abbott Vascular, Santa Clara, CA) in parallel to improve support in the aorta, the AL-2 diagnostic catheter was successfully exchanged for a 6-F AL-2 guiding catheter over the 2 wires. Balloon predilatation was performed with a semicompliant $2.5 \times 15 \mathrm{~mm}$ Emerge balloon (Boston Scientific), and an Orsiro $3.0 \times 18 \mathrm{~mm}$ drug eluting stent (Biotronik, Bulach, Switzerland) was implanted in the mid LCX artery with a thrombolysis in myocardial infarction III flow and the loss of the first marginal branch (Fig. 2C). A thromboaspiration catheter was not used considering the risk of embolization into the left anterior descending in case of partial aspiration of large debris. Creatine kinase and high-sensitivity troponin peaks were $4638 \mathrm{U} / \mathrm{L}$ and 14,798 ng/L, respectively. Transthoracic echocardiography before discharge showed a left ventricular ejection fraction of $50 \%$ and a mean gradient of $6.8 \mathrm{~mm} \mathrm{Hg}$ without paravalvular or central leak. Immediately after procedure, the patient experienced new shortterm memory loss and embolic lesions were observed in the vertebrobasilar territory at cerebral magnetic resonance imaging. The patient was discharged at day 7 on aspirin 100 $\mathrm{mg} / \mathrm{d}$ and clopidogrel $75 \mathrm{mg} / \mathrm{d}$. At 6-month follow-up, the patient was in functional class NYHA-1 but still reported minimal short-term memory loss.

\section{Discussion}

TAVI in bicuspid aortic valve (BAV) remains challenging, especially with respect to sizing due to large annuli, heavily calcified leaflets, and dilated ascending aortas. ${ }^{1}$ Recently, a registry-based cohort study involving 552 US centres compared the results of TAVI in patients with BAV vs TAV stenosis in terms of mortality and stroke. ${ }^{2}$ Although there were no significant differences in 30-day and 1-year all-cause mortality between 2691 propensity-score matched pairs, the stroke rate was significantly higher in patients with BAV at 30 days $(2.5 \%$ vs $1.6 \%)$ but did not significantly differ at 1 year. ${ }^{2}$ Another registry compared $101 \mathrm{BAV}$ and $88 \mathrm{TAV}$ stenosis treated by TAVI with second-generation prostheses. Contemporary computed tomography sizing analysis suggested that annulus-based sizing is accurate in BAV. In addition, an intercommissural distance method can be used in grey zones as well as when intercommissural distance is smaller than the mean annular diameter.

Early ischemic cerebrovascular events mainly occur periprocedurally and are associated with additional device manipulation, postdilatation, and repeated prosthesis positioning. ${ }^{4}$ EPDs emerged as a preventive measure in this context. Debris captured within EPDs can contain fresh or organized thrombus, valve and arterial wall fragments, cardiomyocytes, endothelial strands, collagenous tissue, calcification, and foreign body material. ${ }^{5}$ In our case, redeployments of the valve with additional manipulations contributed to the valvular debris captured in the Sentinel EPD. Importantly, the ischemic cerebral lesions seen on magnetic resonance imaging were in a cerebral area not protected by the EPD (ie, the area vascularized by the left vertebral artery originating from the left subclavian artery).

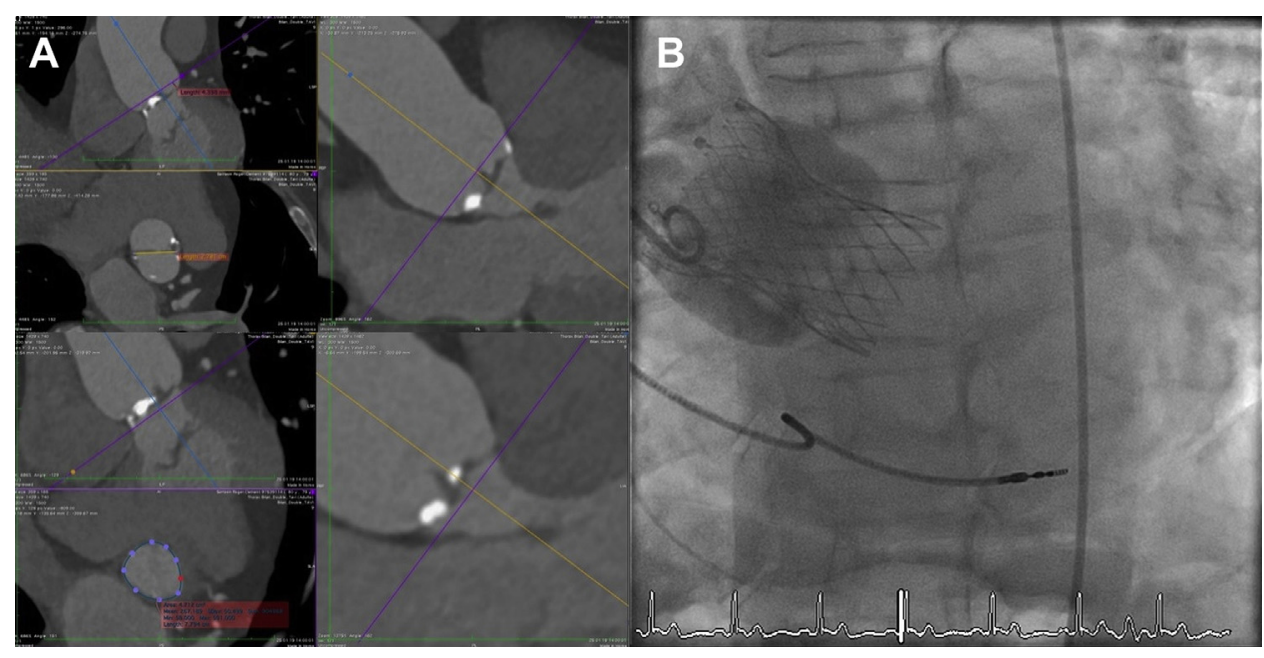

Figure 1. (A) Computed tomography sizing: maximal diameter: $25.5 \mathrm{~mm}$, minimum diameter: $23.4 \mathrm{~mm}$, perimeter: $77.9 \mathrm{~mm}$, derived diameter: $24.8 \mathrm{~mm}$, valve area: $4735 \mathrm{~cm}^{2}$, intercommissural diameter: $27.9 \mathrm{~mm}$; not shown in the figure: Valsalva sinus diameter: $31 \times 44 \mathrm{~mm}$, aorta diameter: $43 \times 44 \mathrm{~mm}$. (B) Aortography showing successful prosthesis deployment. 


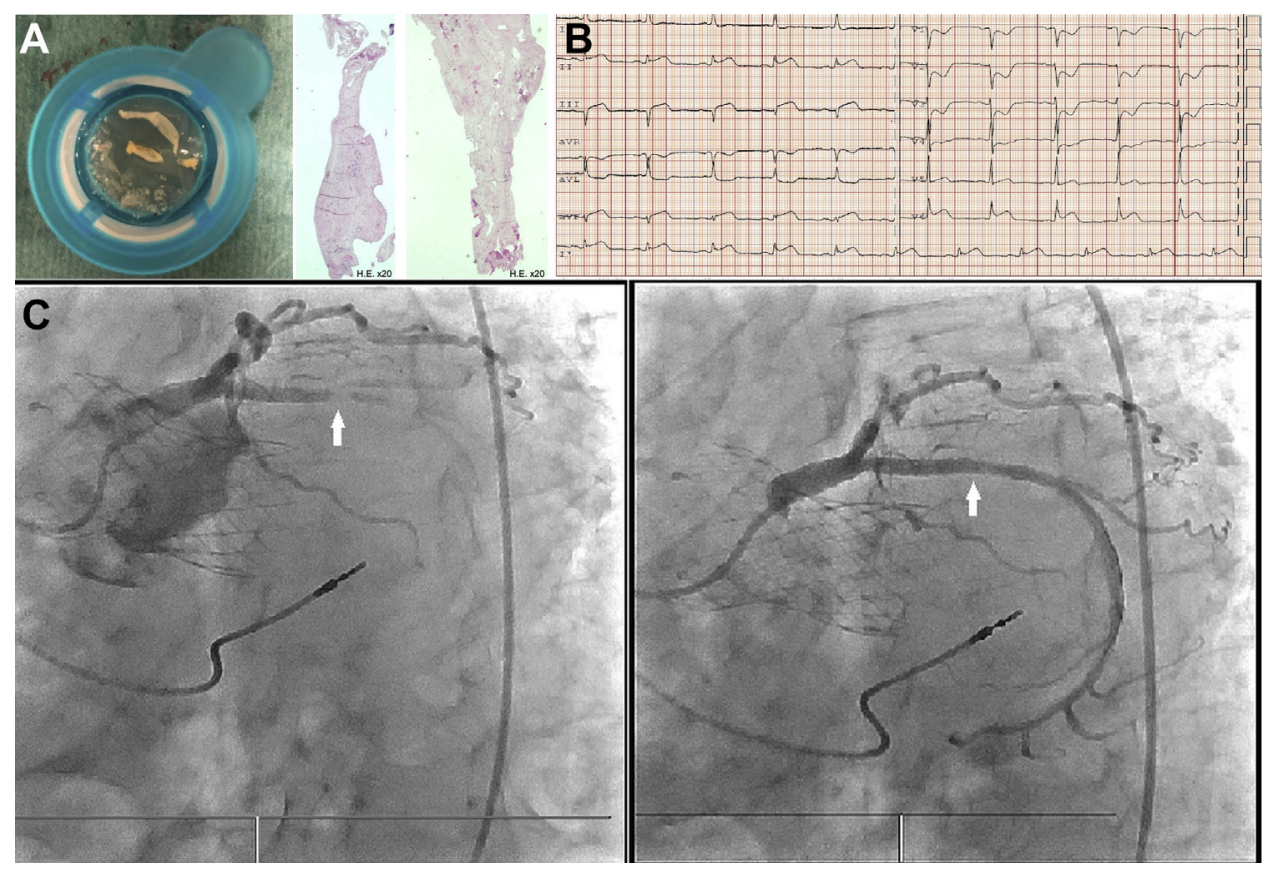

Figure 2. (A) Debris captured within the Sentinel dual filter embolic protection device and histopathology analysis showing valve fragments. (B) Twelve-lead electrocardiogram: ST-segment elevation in the inferior leads and V6 associated with ST-segment depression in V1-V3. (C) Left: angiography showing an acute occlusion of the mid circumflex (LCX) artery (arrow). Right: angiography showing LCX after angioplasty with TIMI III flow and loss of the first marginal branch (arrow). Of note, the coronary ostium was above the highest point of the THV leaflet; therefore, the commissure position did not impact the coronary cannulation. LCX, left circumflex artery; THV, transcatheter heart valve; TIMI III, thrombolysis in myocardial infarction III.

Coronary artery obstruction is a well-known fatal TAVI complication. ${ }^{6}$ However, distal coronary embolization - usually occurring within minutes after valve deployment-is rare. ${ }^{7,8}$

\section{Funding Sources}

This work was funded by GeCor Foundation (Fondation pour la recherche de la cardiologie universitaire de Genève).

\section{Disclosures}

M.C. states no conflict of interest. M.R. received institutional research grants from Biotronik, Medtronic, Boston Scientific, and GE Healthcare. S.N. is a consultant for Medtronic and has received institutional research grants from Medtronic and Edwards Lifesciences.

\section{References}

1. Philip F, Faza NN, Schoenhagen P, et al. Aortic annulus and root characteristics in severe aortic stenosis due to bicuspid aortic valve and tricuspid aortic valves: implications for transcatheter aortic valve therapies. Catheter Cardiovasc Interv 2015;86:E88-98.
2. Makkar RR, Yoon SH, Leon MB, et al. Association between transcatheter aortic valve replacement for bicuspid vs tricuspid aortic stenosis and mortality or stroke. JAMA 2019;321:2193-202.

3. Tchetche D, de Biase C, van Gils L, et al. Bicuspid aortic valve anatomy and relationship with devices: the BAVARD Multicenter Registry. Circ Cardiovasc Interv 2019;12:e007107.

4. Vranckx P, Windecker S, Welsh RC, et al. Thrombo-embolic prevention after transcatheter aortic valve implantation. Eur Heart J 2017;38: $3341-50$.

5. Kroon HG, Van Mieghem NM. Need for embolic protection during transcatheter aortic valve implantation: an interventionalist's perspective on histopathology findings. Interv Cardiol 2017;12:36-9.

6. Ribeiro HB, Nombela-Franco L, Urena M, et al. Coronary obstruction following transcatheter aortic valve implantation: a systematic review. JACC Cardiovasc Interv 2013;6:452-61.

7. Freixa X, Bonan R, Asgar AW. Unusual coronary occlusion post transcatheter aortic implantation: the importance of clinical assessment. Can J Cardiol 2013;29:1014.e5-6.

8. Tsujimura A, Saito N, Minakata K, Kimura T. Distal coronary embolisation during transcatheter aortic valve implantation. BMJ Case Rep 2016;2016:bcr2016216620. 